TI 2006-038/1

Tinbergen Institute Discussion Paper

\title{
Mapping the Minds of Retirement Planners
}

\author{
Douglas A. Hershey \\ Kène Henkens² \\ Hendrik P. van Dalen ${ }^{3}$
}

I Oklahoma State University;

${ }^{2}$ Netherlands Interdisciplinary Demographic Institute (NIDI);

${ }^{3}$ Erasmus University Rotterdam, Tinbergen Institute, and NIDI. 


\section{Tinbergen Institute}

The Tinbergen Institute is the institute for economic research of the Erasmus Universiteit Rotterdam, Universiteit van Amsterdam, and Vrije Universiteit Amsterdam.

Tinbergen Institute Amsterdam

Roetersstraat 31

1018 WB Amsterdam

The Netherlands

Tel.: $\quad+31(0) 205513500$

Fax: $\quad+31(0) 205513555$

Tinbergen Institute Rotterdam

Burg. Oudlaan 50

3062 PA Rotterdam

The Netherlands

Tel.: $\quad+31(0) 104088900$

Fax: $\quad+31(0) 104089031$

Please send questions and/or remarks of nonscientific nature to driessen@tinbergen.nl.

Most TI discussion papers can be downloaded at http://www.tinbergen.nl. 


\title{
Mapping the Minds of Retirement Planners: A Cross-cultural Perspective*
}

\author{
Douglas A. Hershey ${ }^{1}$ \\ Oklahoma State University \\ Kène Henkens ${ }^{2}$ \\ Netherlands Interdisciplinary Demographic Institute (NIDI) \\ and \\ Hendrik P. Van Dalen ${ }^{3}$ \\ Erasmus University Rotterdam and Tinbergen Institute \\ Netherlands Interdisciplinary Demographic Institute (NIDI)
}

April 3, 2006

${ }^{1}$ Department of Psychology, 215 North Murray Hall, Oklahoma State University, Stillwater, Oklahoma 74074. Voice: (405) 744-4594; E-mail: hershey@okstate.edu.

${ }^{2}$ Netherlands Interdisciplinary Demographic Institute, P.O. Box 11650, 2502 AR, Den Haag, the Netherlands. Voice: (+31-70-356-5235. E-mail: henkens@nidi.nl.

${ }^{3}$ Netherlands Interdisciplinary Demographic Institute, P.O. Box 11650, 2502 AR, Den Haag, the Netherlands. Voice: (+31-70-356-5237. E-mail: dalen@nidi.nl

Keywords: retirement, pensions, financial planning, psychology, saving, cross-cultural

\begin{abstract}
This study explored the psychological mechanisms that underlie the retirement planning and saving tendencies of Dutch and American workers. Participants were 988 Dutch and 429 Americans, 25-64 years of age. Analyses were designed to: (a) examine the extent to which structural variables were related to planning tendencies, and (b) develop culture-specific path analysis models to identify the mechanisms that underlie perceived financial preparedness for retirement. Findings revealed striking differences across countries not only among structural variables predictive of key psychological and retirement planning constructs, but also in the robustness of the path models. These findings suggest policy analysts should take into account both individual and cultural differences in the psychological predispositions of workers when considering pension reforms that stress individual responsibility for planning and saving.

* This study was supported in part by a grant to Kène Henkens and Harry van Dalen from the Dutch Foundation for Pensions Studies. This paper was developed while the first author was on sabbatical at the Netherlands Interdisciplinary Demographic Institute in The Hague. The authors benefited from discussions with Joy JacobsLawson during the development of the paper, and they wish to thank Sara Penning, Dave Sherry, and Nicole Rosell for assistance with the data collection. Address correspondence to Douglas A. Hershey, Department of Psychology, Oklahoma State University, 215 North Murray Hall, Stillwater, OK 74078. E-mail: douglas.hershey@okstate.edu.
\end{abstract}




\section{Introduction}

What are the psychological forces that motivate individuals to engage in financial planning for retirement, and how do those forces differ across countries? This is an important question in view of the aging of the population and the reforms in retirement systems that are taking place throughout the Western world. In the United States (U.S.) and throughout Europe, countries are in the process of launching new policy initiatives that shift the responsibility for saving from the state to the individual. Little is known, however, about the psychological mechanisms that predispose individuals to plan and save, and not a single study has examined this topic from a cross-cultural perspective. The broad goal of this paper is to compare the psychological mechanisms that underlie the retirement planning and saving tendencies of Dutch and American workers aged 25-64.

The pension systems in both countries are currently in transition. The Netherlands is in the process of reforming the welfare state by transferring responsibilities from the state to the individual. What this means is that in the future, the planning and saving practices of Dutch workers will have a substantially larger impact on their retirement opportunities and streams of retirement income (Van Dalen \& Henkens, 2002). The U.S. also is in the process of undergoing retirement finance reforms, as witnessed by the massive shift from defined benefit to defined contribution plans, and heated debates over the wisdom of privatizing the Social Security program. By examining cultural differences in the psychological basis of financial planning for retirement, we hope to achieve a better understanding of the opportunities and difficulties societies and individuals can expect to face during this important period of transition.

Over the past two decades, a number of psychological studies on retirement savings have appeared in the literature. Some of this work has been in the area of "behavioral economics," in which the goals have been to identify biases in saving decisions and understand how investors deal with uncertainty (Camerer, Lowenstein, \& Rabin, 2004; Shiller, 1999). A second major line of research-referred to as the "psychographic approach"- - has as its goal to capture the motives that underlie individuals' saving decisions, typically by using a combination of demographic and psychographic variables as predictors (Bagozzi \& Dholakia, 1999; Ehrlich \& Fanelli, 2004; Kassarjian, 1971). Just as demographic variables are commonly used to classify individuals along certain structural dimensions, psychographic variables are used to describe individuals in terms of intrapsychic dimensions by measuring self-reported differences in personality traits, 
opinions, interests, and beliefs (Larson, 1992). The present investigation is guided by this latter research approach.

In this study two empirical objectives are addressed. The first is to examine whether cultural differences exist in the extent to which structural variables are predictive of retirement planning and saving tendencies (as well as the psychological mechanisms that underlie those tendencies). The second goal is to look for cross-cultural differences in a psychomotivational model of the factors that predispose individuals to plan and save. To achieve these goals we analyze comparative data collected from Dutch and American workers aged 20-64.

This investigation stands to make two unique contributions to the literature on retirement planning. First, the model we plan to test is an extension of previous motivational network models of financial planning (e.g., Hershey, 2004; Hershey \& Mowen, 2000; Neukam, 2002). Although each of the variables contained in the proposed model (with the exception of perceived savings adequacy) has been examined as part of other investigations, the variables have never been tested alongside one another in a causal explanatory framework. The second novel aspect of this investigation is that it uses a cross-cultural approach to test the validity of a psychological model of retirement planning. This is done by comparing models based on data collected from the U.S., where savings accumulations are to a large extent the responsibility of the worker, and the Netherlands, in which financial planning decisions are highly centralized and the primary responsibility for retirement financing is carried by the state. Before elaborating on the psychology of retirement planning, the main differences between pension systems in the two countries are described, as well as some of the more important cultural differences surrounding the retirement financing systems.

\section{Two Pension Systems and Cultures Compared}

Old age pension programs traditionally have two main objectives. The first is an insurance function: to help workers maintain an adequate standard of living during retirement by replacing income from work. The second aim is to redistribute income toward low-income pensioners in order to prevent destitution in old age. Pension programs in countries around the world differ widely with respect to how these two objectives are balanced (OECD, 2005; World Bank, 1994), which clearly can be seen by comparing the pension and retirement systems in the U.S. and the Netherlands. 
The Dutch pension system consists of two main tiers, a flat-rate public pension scheme (the so-called old-aged pension law or AOW, comparable to what is commonly referred to as “social security” in the U.S.) and earnings-related occupational plans (referred to in the U.S. as “employer pensions”). Although Dutch employers are not forced to offer pension schemes to their employees, the force of collective wage agreements is strong in the Netherlands and 91 percent of employees are covered by at least some form of occupational pension program. The overwhelming majority of occupational pension contracts - 95 percent in 2004_of are of the defined benefit (DB) type. With DB plans, employees can count on a defined level of retirement income based on a computation that uses their salary and years of service (often up to a maximum of 70 percent of their average salary). Nearly $80 \%$ of occupational pension premiums are paid for by the employer; the remainder is paid by the employee. Post-retirement indexing of benefits is the rule, as virtually all DB pension contracts offer automatic cost-of-living increases. Defined contribution (DC) plans - in which the pension income depends on the specific amount of pension premiums paid—are clearly not favored in the Netherlands. Only three percent of Dutch workers have a DC pension plan.

In addition to these two tiers, there is a third tier — voluntary retirement savings — which until the 1990s played a negligible role for Dutch households. Through voluntary arrangements, individuals can enter into private pension arrangements with insurance companies in order to “top off” their retirement income. These private savings plans are subsidized by the state to cover income shortfalls in old age (i.e., for those with an income replacement rate of less than 70 percent). The role of retirement annuities also is becoming more popular among those who seek early retirement.

Due to the mandatory character of the Dutch pension system, a relatively small number of older individuals are poorly supported in retirement. In fact, in 2003 only six percent of older individuals were living at or below the poverty level. Among Dutch citizens, the low-income elderly are over-represented by single women who worked at part-time jobs before retiring, and first generation immigrants who failed to accumulate sufficient public pension rights before leaving the workforce.

The structure of the U.S. retirement financing system also consists of three tiers. First, there is the social security (i.e., OASDI) program, which is a means tested scheme that is designed to provide an income "safety net” for retirees. For approximately 20 percent of 
Americans of 65 years and older, social security represents their only stream of income (U.S. Dept. of Labor, 2005). The second tier consists of employer-sponsored pensions. In contrast to the Netherlands, in the U.S. employers are not required to provide pension benefits for their employees. Among those employers that do offer pension contracts, they are not required to cover all of their employees (e.g., low income and part-time workers may be excluded from coverage). Employers often require a minimum tenure period before a worker can participate in a pension plan, and a vesting period is routinely applied that limits an employee's access to funds for a pre-specified period of time (e.g., 10 years). In years past most Americans were covered by DB pension plans. Since 1997, however, the number of individuals who participate in DC programs has outnumbered those who participate in DB plans. In fact, as of 2004 some 70 percent of the pension plans in the U.S. are defined in terms of a worker's level of contributions. The most common type of DC program is a 401(k) plan (named for the section in which it is described in the Internal Revenue Service code), in which workers make voluntary saving and investment choices, encouraged by federal tax benefits and employer matching contributions.

To highlight the main differences across countries, in the Netherlands a host of individual risks and responsibilities are carried and organized at a collective level. Moreover, pension funds and government and supplementary pension premiums have a mandatory character. In the United States, the burden of responsibility for retirement saving has to a considerable extent been shifted to the individual worker. Pension plans in the U.S. often have a voluntary character (although many employers make significant contributions to employee pensions), and outcomes are highly uncertain as most pensions rely on DC contracts. Besides pensions and personal savings, older American adults can rely on Social Security, but this safety net is far less than what the Dutch social security system offers.

There are a number of reasons, from a cross-cultural perspective, why one might expect to find differences in retirement planning practices between Dutch and American workers. One reason has to do with the differential opportunity structures (Ekerdt, Hackney, Kosloski, \& DeViney, 2001; O’Rand, 1996; Szinovacz \& Ekerdt, 1995; Van Dalen \& Henkens, 2002) that are available to individuals in the two countries when it comes to financial planning and saving. Consider, for example, the differential saving-related opportunity structures brought about by the availability of employer-sponsored pensions in the two countries. The relative "certainty" of outcomes associated with the Dutch employer pension system helps workers in the Netherlands 
count on an adequate stream of income in old age. In the U.S., in contrast, employer pension programs are not as widespread, and the “uncertain” nature of most DC contracts leave workers unsure as to how adequately they will be supported once they enter retirement. Empirical support for the perceived reality of differences in the two retirement financing systems is reflected in Kreidl's (2000) finding that more Americans than Dutch (42\% vs. 28\%) ascribed socially-based systemic conditions as a key factor leading to poverty.

Based on differences in opportunity structures related to future retirement income, it is not inconceivable that American workers would be more likely to exhibit higher levels of “financial worry” (c.f., Neukam \& Hershey, 2003) than the Dutch. Therefore, one might expect that Americans would be differentially oriented toward retirement planning not only as a coping mechanism, but also to stem the onset of financially-driven retirement anxiety (Hayslip, Beyerlein, \& Nichols, 1997) and help establish predictability and control in this important aspect of their lives.

There are other culturally-based psychological reasons why one might expect to see cross-national differences emerge in not only retirement planning tendencies, but also retirement goals and perceived financial knowledge. Data from a study by Stiles, Gibbons, and Peters (1993) suggest that from as early as adolescence, Americans are indoctrinated to focus on the value of work, earnings, material goods, achievement and independence. In contrast, the importance of work among Dutch adolescents is de-emphasized, and a focus is placed on establishing a high quality of life through cooperation with others and deriving enjoyment from one's experiences. Similar cross-cultural conclusions regarding differences in work values, materialism, and the importance of leisure pursuits have been reported by Ger and Belk (1996), Gauthier and Smeeding (2003), and Hofstede (1976; 1980). Taken together, these findings suggest that American workers should display a greater involvement in retirement planning activities than the Dutch, as well as higher levels of the psychological mechanisms (future orientation, goals, knowledge) that are believed to predispose one to plan.

\section{The Psychology of Retirement Planning}

To examine the psychology of retirement planning between workers in the U.S. and the

Netherlands, five different constructs were examined: (a) future time perspective, (b) retirement goal clarity, (c) perceived financial knowledge, (d) financial planning activity level, and (e) 
perceived savings adequacy. Throughout the remainder of the paper these constructs will collectively be referred to as the psychological and retirement variables. Before discussing the empirical goals of this investigation, a brief review of each of these constructs is provided.

\section{Future Time Perspective}

Future time perspective is a psychological dimension that is purported to tap the extent to which individuals focus on the future, rather than on the present or the past. A handful of recent studies have demonstrated that future orientation is related to the tendency to plan and save. For instance, Lusardi (1999) found that pre-retirees with a low future orientation had not only fewer assets, but they expected to receive less in the way of income from personal savings after they retired. Hershey and Mowen (2000; see also Jacobs-Lawson \& Hershey, 2005) found that future time perspective was positively associated with self-reported financial preparedness for retirement among individuals aged 35-88. Along similar lines, one’s level of patience (i.e., the willingness to postpone spending in order to save) has been shown to be related to retirement saving tendencies (Bernheim, Skinner, \& Weinberg, 1997; Burtless, 1999). Taken together, these findings reveal that the extent of one's future orientation has a significant impact on saving behaviors. A brief version of the Hershey and Mowen (2000) future time perspective scale will be used in the present investigation.

\section{Retirement Goal Clarity}

Psychologists are in strong agreement that goals are central to guiding the enactment of purposeful human behavior (Beach, 1998; Beach \& Mitchell, 1987; Chulef, Read, \& Walsh, 2001; Feather, 1990; Gollwitzer, 1999). It would seem that in the domain of retirement planning, the possession of clear and well-defined goals is a motivational imperative. According to Nurmi (1992; see also Hershey, Jacobs-Lawson, \& Neukam, 2002), older adults frequently cite the achievement of retirement goals as a critical developmental life task, which is consistent with Cantor and Zirkel’s (1990) theoretical notion of “age-graded normative goals” (see also Cantor \& Kihlstrom, 1987). A few recent studies have demonstrated the impact of retirement goals on the tendency to plan and save. For instance, Glass and Kilpatrick (1998) found that making retirement saving a priority was related to the magnitude of individuals' financial accumulations. Neukam and Hershey (2003) demonstrated that financial goal strength was 
related to retirement savings contributions. Stawski, Hershey, and Jacobs-Lawson (2005) found that general retirement goal clarity was related to financial planning activity level, and Hershey, Mowen, and Jacobs-Lawson (2003) found that the presence of goal-based content in a saving intervention seminar had a positive impact on the tendency to plan. Taken together, these findings underscore the importance of setting clear and meaningful financial goals for retirement. What has yet to be empirically established, however, is the mechanism by which those goals exert their influence on the tendency to save. In the present study, a general retirement goal clarity measure will be used as a predictor of retirement planning practices.

\section{Knowledge of Financial Planning for Retirement}

Of the various psychological constructs that have been studied in relation to savings, perhaps none has received as much attention as financial knowledge. It is positively related to retirement planning activities (Ekerdt \& Hackney, 2002), financial saving practices (Chan \& Stevens, 2003; Grable \& Lytton, 1997; Hershey \& Mowen, 2000; Yuh \& DeVaney, 1996), and the quality of individuals’ financial and investment decisions (Hershey \& Walsh, 2000/2001; Walsh \& Hershey, 1993). Mitchell and Moore (1998) concluded that individuals fail to plan for retirement because they lack sufficient domain-specific knowledge, and Hershey, Brown, Jacobs-Lawson, and Jackson (2001) found that retirees report feeling they should have become more knowledgeable about savings and investments. Grable and Lytton (1997) found that investment knowledge is positively related to saving behaviors. Taken together, these findings indicate that knowledge of financial planning for retirement has a profound effect on retirement saving decisions.

In the present study, a perceptual measure of financial knowledge will be used. Although perceptual knowledge measures may lead to certain subjective biases not found among “objective” financial knowledge indicators (i.e., individuals may think they know more than they actually know), they are more efficient and easier to administer than their more objective counterparts (Flynn \& Goldsmith, 1999). Moreover, at least three different studies have shown that scores on perceptual knowledge tests are positively correlated with scores on objective financial knowledge measures (Goldsmith \& Goldsmith, 1997; Goldsmith, Goldsmith, \& Heaney, 1997; Hershey, 1990). 


\section{Financial Planning Activity Level}

Financial planning activities encompass a wide range of behaviors, and accordingly, the construct has been defined in a variety of ways. However, despite differences in how planning activities have been operationally defined, they have been shown to be related to individuals' saving practices (Stawski et al., 2006), feelings of retirement preparedness (Moen, Erickson, Agarwal, Fields, \& Todd, 2000) and retirement satisfaction levels (Taylor \& Doverspike, 2003). Lusardi (1999) found that heads of households who had not engaged in planning activities had accumulated less wealth than households in which the head had done some planning, and Ameriks, Caplin, and Leahy (2002) reached similar findings. Despite the apparent significance of engaging in planning activities, findings from the Retirement Confidence Survey revealed that only about one-third of American workers have spent the time required to calculate how much they will need to save for retirement, and some 37\% of workers have given little or no thought to their retirement whatsoever (Yakoboski \& Dickemper, 1997; see also Ameriks et al., 2002). In the present study, a financial planning activity scale was used that was designed to measure whether individuals had calculated their savings needs and gathered information about retirement preparation.

\section{Perceived Savings Adequacy}

A subjective measure of savings adequacy is employed in the present study in order to gauge whether individuals believe they are saving enough to retire comfortably. Examining individuals’ perceptions of savings adequacy represents an important extension of previous work, which has generally relied on econometric indices of retirement savings (e.g., individual saving rates, retirement plan contributions). Kemp, Rosenthal, and Denton (2005) have argued that it is critical to tap subjective (as opposed to strictly objective) indicators of financial planning for late life, because it is the former that structures individuals’ perceptions of financially-related opportunities and constraints. Another reason it is important to examine subjective indicators of saving is because negative perceptions have been shown to lead to "retirement anxiety" (cf., Hayslip et al., 1997) and ultimately, difficulties in adjusting to retirement (Van Solinge \& Henkens, 2005). Those who perceive their savings to be sufficient should be less likely to develop retirement anxiety and more likely to develop positive levels of investor confidence and financial planning self-efficacy. 


\section{Goals of the Present Investigation}

The first empirical objective of this study is to examine whether cultural differences exist in the extent to which structural variables are predictive of the psychological and retirement variables. To this end, a series of nation-specific ordinary least squares (OLS) regression models will be estimated. Because no previous investigations have explored cultural differences among these constructs, for this set of analyses, no a priori directional hypotheses were made regarding group differences.

The second objective is to test the psychological model of financial planning shown in Figure 1. Based on well established findings regarding the effect of planning on saving (Lusardi, 1999, 2000), it is predicted that planning activities will be positively related to perceived savings adequacy (path a), and perceived financial knowledge will be positively related to planning activity level (path b; Bernheim, 1998; Hershey \& Mowen, 2000). It is further expected that goal clarity will be positively related to perceived financial knowledge (path c), and future time perspective will be positively related to goal clarity (path d; Neukam, 2002). Finally, goal clarity is expected to be positively related to planning activities (path e; Bagozzi \& Dholakia, 1999; Gollwitzer, 1999; Neukam, 2002; Stawski et al., 2005), and future time perspective is expected to be positively related to perceived financial knowledge (path f, Hershey \& Mowen, 2000; Neukam, 2002).

The predictions specified in the hypothesized model (outlined above) are based not only on previous empirical findings, but they also are grounded in two broader psychological theories. Specifically, we drew heavily upon Beach’s Image Theory (Beach, 1998; Beach \& Mitchell, 1987) when developing our predictions, as well as Mowen's 3M Theory of Personality (Mowen, 2000). Both theoretical models were conceptually useful because they outline, in broad terms, a proposed sequence of relationships among personality constructs (such as future time perspective), cognitive constructs (such as goal clarity and financial knowledge) and behavior (such as retirement planning activities).

According to Mowen (2000), in psychomotivational network models such as the one we propose to test, personality constructs should be cast as distal predictors of behavior. Personality variables in the $3 \mathrm{M}$ theory are always specified to underlie cognitive constructs, the latter of which typically serve as proximal predictors of behavior. A similar organizational framework can be found in Beach's (1993) Image Theory, which is designed to explain how individuals' 
goals serve to shape behavior. According to Beach, goals are influenced by elements of one’s “value image," which is heavily influenced by a variety of individual difference dimensions (including personality traits). Individuals’ long-range goals (referred to by Beach as a “trajectory image”), in turn, serve to specify a behavioral plan (a "strategic image”) that will ultimately lead to goal fulfillment.

Based on the tenets of these two theories, in the current investigation one could think of variability in future time perspective as exerting a causal influence on the development of individuals (cognitive) goals and perceived financial knowledge. The two cognitive variables, in turn, can be expected to exert a proximal influence on retirement planning behaviors. We would further contend that perceptions of one's retirement savings adequacy should be the result of active engagement in the retirement planning and saving process, thus providing a rationale for the link between these two variables. We would be remiss if we failed to mention that it is likely the case that there are both "feed-forward" and "feed-backward" influences among variables in the model, making it a more dynamic and recursive structure than the model portrayed in Figure 1. For example, one's perceived financial knowledge may have not only a feed-forward influence on planning activities, but engagement in planning activities may (through a feed-back mechanism) lead to increases in knowledge. However, short of using a multi-year longitudinal design, it would not be possible to test for these dynamic recursive effects. Our empirical goal in this study was admittedly more modest and pragmatic. By modeling data derived from a single occasion of measurement, we sought to obtain a "snapshot" representation of the feed-forward relationships among variables.

Consistent with the overarching goal of testing for cross-cultural differences in financial planning, separate path models will be constructed for Dutch and American respondents. It will be of particular interest to see whether the same basic structural configuration emerges for respondents from the two countries and whether the magnitudes of path coefficients are comparable to one another.

\section{Method}

\section{Participants}

Dutch participants were a subset of working individuals 25-64 years of age drawn from a larger 
national study on attitudes toward old age and retirement (Van Dalen \& Henkens, 2005a).

Working individuals were selectively included in this investigation because each would leave the labor market at some point in the future, and therefore, each faced the decision of whether to prepare and save for retirement. Moreover, all participants were drawing an income at the time they were surveyed, and therefore, potentially had resources that could be used to save and invest.

The Dutch data were collected by the CentERdata databank at the University of Tilburg (for more details see www.centerdata.kub.nl). CentERdata maintains a representative Internetbased panel of 2,000 households in the Netherlands. Dutch females are underrepresented in the present sample (621 men; 367 women) due to the fact that a large proportion of married women in the Netherlands do not participate in the labor market (cf. Henkens, Grift \& Siegers, 2002).

American respondents (206 men; 223 women) also were working adults 25-64 years of age. They were sampled from public places (e.g., libraries, community group meetings and sporting events) in the North Central Oklahoma area. Besides the use of different methodologies for sampling respondents in the two countries, the Dutch and American groups differed along certain demographic dimensions. Relative to the Dutch, the American sample was somewhat older, more highly educated, and slightly overrepresented by female respondents. Members of the Dutch sample, in contrast, were found to have higher annual household incomes (see Table 1). Certain of these demographic variables have been shown to be predictive of retirement attitudes, knowledge, and beliefs. Therefore, to ensure that pre-existing differences in the composition of the samples would not influence either the descriptive statistics reported, or the evaluation of the psychological model of planning, cross-national group differences in age, gender, income, and education have been statistically equated in these analyses.

\section{Description of Measures}

Table 2 contains a description of each of the major psychological and retirement measures used in this investigation. This table includes mean scores, standard errors, p-levels for tests of between-group mean differences, scale characteristics, a sample item from each measure, and coefficient alpha values. Also identified in this table are the original sources for the scales, from which individual items were selected for this study. Items for all five scales used the same 5point Likert-type response format. Furthermore, as mentioned above, estimated mean scores are 
reported in which age, gender, education, and income have been controlled.

Following the recommendations of Poortinga (1989) and Van de Vijver and Leung (1997) a check was made to ensure that the meaning of items for the four scales were comparable across cultures. To this end, eight separate factor analyses using principalcomponents analysis were conducted (one for each nationality for each of the four multi-item scales). According to Dam-Baggen, Kraaimaat, and Elal (2003) correspondence in factor structure across different cultural groups allows one to infer that the psychological constructs underlying the two versions of a scale are identical. For both Dutch and American respondents, all four of the scales were found to have a dominant single-factor structure, and the observed factor loadings did not vary appreciably across groups. Taken together, these findings provide empirical support for the comparability of the measures and the integrity of the translation process.

Compared to Dutch respondents, Americans had significantly longer future time perspectives, higher levels of retirement goal clarity and they tended to be more engaged in retirement planning activities. Dutch respondents, in contrast, had a higher mean score on the measure of perceived savings adequacy. The perceived financial knowledge scores failed to reveal a difference between groups.

The four socio-demographic indicators-age, gender (males $=1$; females $=2$ ), annual household income, and level of education-were measured in the conventional fashion. Level of education was measured by transforming it to effective years of education. Income levels for the Dutch were measured in Euros and converted to U.S. dollars for reporting purposes.

\section{Results}

In this section two separate sets of analyses are reported. The first involves using structural variables to explain variability in the five psychological and retirement planning constructs and the second involves testing for cross cultural differences in the psychological model shown in Figure 1.

\subsection{Role of Structural Factors in the Financial Planning Process}

Analysis Plan

We begin by examining the extent to which the four structural variables in the investigation 
predict each of the psychological and retirement constructs. To this end, ten separate nationspecific OLS regression models (five Dutch; five American) are computed using age, gender, annual household income, and level of education as predictors.

\section{Findings}

Table 3 shows the results of the regression analyses described above. In the first and second pairs of columns standardized beta weights (and accompanying $t$-values) are presented for American and Dutch workers, respectively. In the last column it is indicated whether the beta weights significantly differ across nationalities.

For American workers, annual household income has a strong effect on each of the five constructs. Workers with higher household incomes have a stronger future time perspective, clearer retirement goals, and higher levels of perceived financial knowledge. Moreover, highincome workers have a higher retirement planning activity level and they perceive their retirement savings as more adequate. In addition to the effects of income, there is a gender bias operating with respect to financial knowledge, retirement planning activity level, and perceived savings adequacy (compared to males, females had lower scores on each of these variables). Finally, for members of both groups, age is positively related to retirement goal clarity level.

For the Dutch, the explained variance in the models proved to be substantially lower than for Americans. The one exception to this was for retirement goal clarity, in which the Dutch $R^{2}$ value was nominally higher. The table also reveals that the effect of household income among Dutch respondents is much weaker in all five regression models than it is among Americans. In fact, among the Dutch, household income is significantly related only to perceived financial knowledge. Interestingly, age in the Dutch sample has a stronger influence on retirement goal clarity than in the American sample, which suggests that among Dutch workers, goals for retirement develop at a later age than among workers in the U.S. It also was observed that future time perspective increases with age among Dutch workers, which was not the case among Americans. Moreover, the gender bias with regard to perceived financial knowledge is stronger in the Dutch sample, which probably is due to the (still dominant) traditional division of household tasks in the Netherlands, in which the male maintains the role of the primary household financial planner. 


\subsection{Psychological Model of Financial Planning for Retirement}

\section{Analysis Plan}

In this section, analyses are described in which the psychological and retirement variables are examined as part of an integrative model. This is accomplished by using hierarchical regression techniques to compute separate path analysis models for Dutch and American participants. This analytic approach makes it possible to enter predictors for endogenous variables one at a time. From an empirical perspective, this allows us to determine the effect of a predictor at one hierarchical level after first having removed the variance associated with predictors from all previous levels. Due to the relatively high levels of statistical power associated with the path analyses, the models presented below have been trimmed of paths with standardized beta weights between -.20 and .20. This was done to avoid over-interpreting the importance of trivially small but statistically significant effects. ${ }^{1}$

As mentioned in the method section, the four structural variables in the study (age, income, gender, and education) were covaried out of the equations. This was done because (a) levels of these variables were found to differ somewhat across nationalities, and (b) these variables are differentially related to the retirement constructs for Dutch and American participants. Therefore, their use as covariates in the path analyses is an attempt to level the playing field across groups. By statistically removing the effect of these structural indicators (i.e., potential confounders in the present context), we were able to test the psychological models in a relatively "pure” fashion.

\section{Findings: Dutch Path Model}

The Dutch path analysis was based on the computation of four separate hierarchical regressions, one for each endogenous variable. As seen in Figure 2, for Dutch participants 25 percent of the variability in perceived savings adequacy was captured. Following removal of the covariates in level one, in the second level retirement planning activity scores were shown to be related to perceived savings, standardized Beta $=.48, p<.01$. The remaining three variables (perceived financial knowledge, goal clarity, and future time perspective) were trimmed from the model as they failed to exceed the minimum .20 beta weight threshold in the first stage of the analysis.

The second hierarchical regression model accounted for 23 percent of the variance in retirement planning activity levels. Following removal of the covariates, in the second 
hierarchical level perceived financial knowledge was shown to predict planning activity scores, Beta $=.31, p<.05$, and goal clarity emerged as a significant predictor in level three, Beta $=.36$, $p<.01$. Future time perspective, which had a relatively small beta weight in the first stage analysis, was trimmed from the model.

The third regression analysis captured 17 percent of the variance in financial knowledge scores. Following removal of the covariates, retirement goal clarity in the second level emerged as a significant predictor (Beta $=.26, p<.01$ ), as did future time perspective in level three (Beta $=.21, p<.01)$.

The final regression analysis accounted for 30 percent of the variance in retirement goal clarity. Following removal of the covariates, in the second hierarchical level future time perspective was found to exceed the significance threshold, Beta $=.41, p<.05$.

\section{Findings: American Path Model}

As was the case with the Dutch model, the American path model (Figure 3) was constructed based on four separate hierarchical regressions. The first model, designed to predict participants' perceived savings adequacy, accounted for 53 percent of the variance in the construct. Following removal of the covariates, in the second hierarchical level planning activities emerged as significant (Beta $=.63, p<.01$ ), as did future time perspective in level three (Beta $=.26, p<$ $.01)$. Paths trimmed from this analysis included perceived financial knowledge to perceived savings, and retirement goal clarity to perceived savings.

The second regression model, designed to account for variability in planning activity levels, captured 61 percent of the variance in the construct. Following removal of the covariates, both perceived financial knowledge and goal clarity were significant predictors in levels two and three, respectively (Beta $=.65$ and .34 , both $p<.01$ ). The standardized beta weight for future time perspective to planning had previously been shown to be small, therefore, it was trimmed from the analysis.

In model three, 37 percent of the variability in perceived financial knowledge was explained. Following removal of the covariates, in the second level retirement goal clarity exceeded the significance threshold (Beta $=.43, p<.01$ ), as did future time perspective in level three $($ Beta $=.32, p<.01)$.

The final hierarchical model explained 37 percent of the variance in retirement goal 
clarity. Following removal of the covariates, in this analysis future time perspective exceeded the significance threshold, Beta $=.53, p<.01$.

As a final step in the development of the Dutch and American models, the beta weights of parallel paths were compared using the Chow test of equality between linear regression coefficients (Chow, 1960). Among the seven sets of paths, five were found to be statistically significantly stronger in the American sample: (a) planning to savings adequacy, $t(1413)=5.26$, $p<.01$, (b) perceived financial knowledge to planning, $t(1413)=8.76, p<.01$, (c) goal clarity to perceived financial knowledge, $t(1413)=6.89, p<.01$ (d) future time perspective to goal clarity, $t(1413)=4.73, p<.01$, and (e) future time perspective to perceived financial knowledge, $t(1413)$ $=5.42, p<.01$. The path from future time perspective to savings adequacy differed at the level of a trend $(t[1413]=1.73, p<.10)$, and no difference was found across slopes for the goal clarity to planning activities path $(t[1413]=.39, n s)$.

\section{Discussion and Conclusions}

In this paper we examined the psychology of retirement planning from a cross-cultural perspective. The data seem to indicate that Dutch workers are less involved in retirement planning activities and have lower goal clarity scores than Americans, yet they have higher scores on the measure of perceived savings adequacy. The former two findings reflect important systemic differences when it comes to retirement financing, as the primary burden of Dutch workers' retirement income is shouldered not by the individual, but rather, by one's employer and the state. The latter finding - that Dutch workers perceive their retirement savings as more adequate than Americans_-reflects the comprehensive nature of the Dutch retirement income "safety net." This relatively high level of perceived savings may partly be a result of the fact that pension obligations in the Netherlands are typically defined in terms of a percentage of one's final or average pay, as opposed to being defined in terms of one's contributions. Thus, Dutch workers are in a position to be relatively certain about how much they can expect to receive in retirement irrespective of their level of involvement in the financial planning process. The high levels of perceived savings adequacy also may be related to the high levels of confidence Dutch workers have in their pension programs. Recent figures from Van Dalen and Henkens (2005b) show that only 13 percent of employees in the Netherlands distrust those who manage their pension funds. This finding stands in stark contrast to the situation in America, where seriously 
under-funded pension programs, weak regulatory policies, and the lack of full disclosure from pension fund mangers have created anxiety and distrust among present and future pensioners (Moore, 1995).

Interesting similarities and differences also were found between countries in the relationships among structural socio-demographic variables and the psychological and retirement planning constructs. Age proved to be a much stronger predictor of goals for Dutch workers than it was for Americans, who had stronger goals earlier in adulthood than their Dutch counterparts. ${ }^{2}$ This notion that workers in the U.S. are trained to begin thinking about retirement early in adulthood is reflected in Ekerdt’s recent claim that Americans are “born to retire.” By strengthening retirement saving norms and expectations, he argues, “American workers will think, prepare, and save more for retirement...beginning in early adulthood” (p. 5, 2004).

The findings from this study also revealed that for American workers, making retirement planning a priority is strongly related to their level of financial resources. Individuals with lower incomes not only had weaker future time perspectives, but they also displayed low levels of goal clarity, perceived financial knowledge, retirement planning activity levels, and perceived savings adequacy. Interestingly, we did not find statistically significant relationships between income and the various dependent measures in the Netherlands, which suggests that the absence of a strong retirement planning orientation among the Dutch is true irrespective of one's earning power.

An important conclusion with regard to gender inequality is that in both countries women tended to be less involved in retirement planning and preparation. They had weaker goals for retirement and they perceived their retirement savings to be less adequate than did men. These similarities are important in view of the fact that social support systems tend to be inherently unfair to women in terms of how they have been traditionally structured, not only in the U.S. (ISSA, 2004), but also in countries across Europe (UNECE, 2004). We speculate that the lower levels of retirement involvement seen among Dutch and American women in this study are largely due to the historical division of labor in both countries. Men (particularly older men) are more likely to be not only the primary wage earners, but also the ones who are responsible for managing family finances.

We now turn our attention from the structural analyses to the path analysis models. In general, both the Dutch and American models closely reflected the hypothesized model shown in 
Figure 1. The only exception was an unanticipated path in the American model between future time perspective and perceived savings adequacy. On the one hand, from a theoretical perspective this is a reassuring finding. One would not expect to find qualitative differences across cultures in the psychological mechanisms that underlie planning tendencies. On the other hand, quantitative differences were clearly observed with respect to the robustness of the two models. Specifically, the explained variance in the American model was two to three times higher than it was in the Dutch model for perceived savings, planning activities, and perceived financial knowledge. These findings indicate the existence of more highly systematic relationships among predictors and endogenous variables among Americans, which presumably stem from programs and policies that stress individual financial responsibility. The relative lack of explained variance in the Dutch model presumably stems from the fact that planning activities largely have been outsourced to various centralized pension organizations, which leaves little reason for individual Dutch workers to cultivate a strong psychological planning orientation. By examining planning practices cross culturally, we have successfully broadened the empirical base of an emerging psychological model of retirement planning (e.g., Hershey \& Mowen, 2000; Neukam, 2002; Stawski et al, 2005) that until this point, had been exclusively tested on samples of Americans.

Another apparent difference between the Dutch and American path models involves the impact of future time perspective on retirement preparation. Not only were Americans' future time perspective scores significantly larger, but the predictive effect of time orientation on retirement goal clarity also was significantly higher for this group. Moreover, for Americans, future orientation had a direct effect on perceived savings adequacy — an effect not observed in the Dutch model. It remains to be established, however, why it is that the Dutch have a significantly lower future time perspective. Perhaps it is not the case that the Dutch future time perspective was low, but rather, that Americans had a relatively high future time perspective based on the strong cultural indoctrination toward thinking about and preparing for the future (Ekerdt, 2004; Stiles et al., 1993).

In sum, the findings from this study suggest that cultural factors may lie at the heart of the observed cross-national differences. The country-based effects witnessed in both the structural analyses and psychological models are consistent with two divergent societies in which there exist major differences in individual financial responsibility, different levels of uncertainty 
surrounding future pension payouts, and differences in the psychological pressures faced by workers as they attempt to ensure the adequacy of their own financial futures. In the U.S., the pressure to plan and save is arguably a central facet of Americans' cultural awareness. Not all American workers are successful at this task - in fact, many fail to plan and save at suboptimal levels_-but all, it would seem, are acutely aware of the consequences of their behavior. The findings from this study suggest that this same level of "retirement mindedness" may not be as prevalent in the Netherlands, where government and corporate control of pension benefits help serve to insulate the worker from the same degree of planning-related psychological stress.

It is tempting to interpret at face value the observed cross-national differences among the financial and retirement planning constructs. The most enticing interpretation of these effects is that they stem from the different savings-oriented opportunity structures that exist in the Netherlands and the U.S., as well as from differences in social pressures that flow from the ortgeist (i.e., spirit of the place), which stimulate involvement in financial and retirement planning activities. However, one needs to be cautious in adopting such an explanation, in light of studies that suggest cultural differences exist in how individuals respond to Likert-type rating scales (i.e., the type used in this investigation). Studies by Tanzer (1995) and Van Herk, Poortinga, and Verhallen (2004) reveal that individuals from different countries adopt different response styles when making Likert ratings, thus making it difficult to explain the observed cross-national differences exclusively on the basis of structural opportunities or intrapsychic dimensions (e.g., goal clarity; future orientation). Although we could find no studies to suggest that Dutch and American respondents differ in their orientation to Likert-type items, there exists the possibility that some unknown form of scale-related response bias may have been operating.

Another possible artifactual explanation for at least some of the observed cultural differences stems from the fact that individuals from different countries have been shown to display systematic biases when making confidence ratings (Lundeberg, Fox, Brown, \& Elbedour, 2000). In the present study, it is possible that a bias in confidence levels may have affected not only respondents' ratings of perceived knowledge, but also their perceived savings adequacy scores. Although Lundberg et al. failed to find substantive confidence differences between Dutch and American students when it came to performance on an academic exam, confidence biases may exist when individuals are asked to evaluate their personal financial situation (c.f., Hershey \& Wilson, 1997). 


\section{Implications, Limitations, and Future Directions}

The Netherlands and other European welfare states are presently considering a variety of different retirement finance reforms, which will ultimately have the effect of increasing individual levels of financial responsibility (Reday-Mulvey, 2005). Policy changes also are afoot in the U.S., where debates are being held over privatized retirement accounts and the extent to which workers should be entrusted to manage their own resources. Policies under consideration in both countries have been developed based on the assumption that a large portion of the burden of planning responsibilities previously carried out by the government (or other financial collectives) can be successfully shouldered by the worker. The ultimate success of this transfer of responsibility will depend not only on workers' willingness to accept the proposed changes, but also on the extent to which they are psychologically prepared to rise to the challenge. That is, simply changing the incentive structures that govern the retirement saving process would not ensure individuals have the skills, aptitudes and abilities to become competent investors. Consider Australia as a case in point. To this day large numbers of workers are still hesitant to actively manage their own portfolios (Clark-Murphy, Kristofferson \& Gerrans, 2002) despite the fact that major privatization reforms establishing individual accounts took place over a decade ago. Presumably, this lack of involvement in the financial planning process translates into proportionally more households that will fail to accumulate sufficient savings to meet their financial needs.

The present study is not without limitations. One limitation involves the exclusive focus on "feed-forward" influences on behavior, represented as right-facing arrows in the three figures. Not studied were negative feedback loops (i.e., influences believed to exist that would be represented by left-facing arrows). Dynamic cybernetic models, which contain causal influences that flow in both directions, are fundamental to general systems theory approaches (von Bertalanffy, 1967) and not uncommon in recent psychological theories (cf., Mowen, 2000; Carver and Scheier, 1998, 1999). Unfortunately, the task of empirically modeling feedback pathways can be challenging, requiring the use of either a complex developmental design (which is typically costly) or retrospective reports (which may suffer from questionable validity). Despite the difficulties involved, however, it would seem that studying both types of effects (i.e., forward- and back-flowing influences) should be made a priority in future investigations. 
Other limitations of this study have to do with the nature of some of the scales and variables used. For example, a single-item indicator was used to assess perceived savings adequacy. We would argue that in future studies this measure should not only be expanded into a multiple-item scale, but it also should be examined in relation to more traditional econometric indicators of savings. The latter objective would allow researchers to assess the extent to which there are systematic biases in individuals' savings perceptions, and identify groups of individuals that reliably over- or underestimate their retirement nest egg. Similarly, perceptions of financial knowledge were assessed (rather than actual financial knowledge), which may have led individuals to over- or underestimate how much they knew about financial preparation for retirement. It is unclear whether systematic (i.e., cross-national) perceptual biases were associated with either financial knowledge or perceived savings, and if they did exist, how any such differences may have affected the findings. Open questions remain, however, regarding the validity of these two measures, which suggests that more psychometrically-oriented investigations are warranted that examine the possibility of cross-cultural differences in perceptual biases.

\section{Conclusion}

Taken together, the findings from this study suggest that personal economic decisions do not take place in a psychological vacuum. Rather, social forces have a pronounced impact on the predisposition to plan and save, which is a finding that has important real-world implications for future policy initiatives designed to stimulate planning tendencies among future cohorts of retirees. The success of any such future policy initiatives will depend, we believe, on a twopronged approach that stresses not only changing the financial incentives that govern investment behaviors, but also changing the dimensions of the psyche that motivate individuals to adaptively prepare for old age. 


\section{References}

Ameriks, J., Caplin, A., \& Leahy, J. (2002). Wealth accumulation and the propensity to plan. NBER Working Paper Series \#8920. Cambridge, MA: National Bureau of Economic Research.

Bagozzi, R. P., \& Dholakia, U. (1999). Goal setting and goal striving in consumer behavior. Journal of Marketing, 63, 19-32.

Beach, L. R. (1993). Image theory: Personal and organizational decisions. In G. A. Klein, J. Orasanu, R. Calderwood, and C. E. Zsambok (Eds.), Decision making in action (pp. 148157). Westport, CT: Ablex.

Beach, L. R. (1998). Image theory: Theoretical and empirical foundations. Mahwah: NJ: Erlbaum.

Beach, L. R., \& Mitchell, T. R. (1987). Image theory: Principles, goals, and plans in decision making. Acta Psychologica, 66, 201-220.

Bernheim, B. D. (1998). Financial illiteracy, education, and retirement saving. In O. Mitchell \& S. Schieber (Eds.), Living with defined contribution pensions (pp. 38-68). Philadelphia: Pension Research Council.

Bernheim, B. D., Skinner, J., \& Weinberg, S. (1997). What accounts for the variation in retirement wealth among U.S. households? NBER Working Paper Series \#6227. Cambridge, MA: National Bureau of Economic Research.

Burtless, G. (1999). An economic view of retirement. In H. J. Aaron (Ed.), Behavioral dimensions of retirement economics (pp. 7-42). Washington D.C.: Brookings Institution Press.

Camerer, C. F., Lowenstein, G., \& Rabin, M. (2004). Advances in behavioral economics. New York: Russel Sage Foundation.

Cantor, N., \& Kihlstrom, J. F. (1987). Personality and social intelligence. Englewood Cliffs, NJ: Prentice-Hall.

Cantor, N., \& Zirkel, S. (1990). Personality, cognition, and purposeful behavior. In L. A. Pervin (Ed.), Handbook of personality: Theory and research (pp. 135-164). New York: Guilford Press.

Carver, C. S., \& Scheier, M. F. (1998). On the self-regulation of behavior. New York: Cambridge University Press. 
Carver, C. S., \& Scheier, M. F. (1999). Themes and issues in the self-regulation of behavior. In R. S. Wyer, Jr. (Ed.), Advances in social cognition, Vol. 12 (pp. 1-105). Mahwah, NJ: Erlbaum.

Chan, S., \& Stevens, A. H. (2003). What you don’t know can’t help you: Pension knowledge and retirement decision making. NBER Working Paper Series, \#10185. Cambridge, MA: National Bureau of Economic Research.

Chow, G. C. (1960). Tests of equality between sets of coefficients in two linear regressions. Econometrica, 28, 591-605.

Chulef, A. S., Reed, S. J., \& Walsh, D. A. (2001). A hierarchical taxonomy of human goals. Motivation \& Emotion, 25, 191-232.

Clark-Murphy, M., Kristofferson, J., \& Gerans, P. (2002). What makes superannuation decisions difficult? International Journal of Business Studies, 10, 73-94.

Dam-Baggen, R., Kraaimaat, F., \& Elal, G. (2003). Social anxiety in three Western societies. Journal of Clinical Psychology, 59, 673-686.

Ehrlich, E., \& Fanelli, D. (2004). The financial services marketing handbook: Tactics and techniques that produce results. Princeton, NJ: Bloomberg Press.

Ekerdt, D. J. (2004). Born to retire: The foreshortened life course. The Gerontologist, 44, 3-9.

Ekerdt, D. J., \& Hackney, J. K. (2002). Workers’ ignorance of retirement benefits. The Gerontologist, 42, 543-551.

Ekerdt, D. J., Hackney, J. K., Kosloski, K., \& DeViney, S. (2001). Eddies in the stream: The prevalence of uncertain plans for retirement. Journal of Gerontology, 56B, S162-S170.

Feather, N. T. (1990). Bridging the gap between values and actions: Recent applications of the expectancy-value model. In E. T. Higgins \& R. M. Sorrentino (Eds.), Handbook of motivation and cognition: Foundations of social behavior, Vol. 12 (pp. 151-192). New York: Guilford Press.

Flynn, L. R., \& Goldsmith, R. E. (1999). A short, reliable measure of subjective knowledge. Journal of Business Research, 46, 57-66.

Gauthier, A. H., \& Smeeding, T. M. (2003). Time use at older ages: Cross-national differences. Research on Aging, 25, 247-274.

Ger, G., \& Belk, R. W. (1996). Cross-cultural differences in materialism. Journal of Economic Psychology, 17, 55-77. 
Glass, J. C., \& Kilpatrick, B. B. (1998). Gender comparisons of baby boomers and financial preparation for retirement. Educational Gerontology, 24, 719-745.

Goldsmith, E. B., \& Goldsmith, R. E. (1997). Gender differences in perceived and real knowledge of financial investments. Psychological Reports, 80, 236-238.

Goldsmith, R. E., Goldsmith, E. B., \& Heaney, J. (1997). Sex differences in financial knowledge: A replication and extension. Psychological Reports, 81, 1169-1170.

Gollwitzer, P. M. (1999). Implementation intentions. American Psychologist, 54, 493-503.

Grable, J. E., \& Lytton, R. H. (1997). Determinants of retirement savings plan participation: A discriminant analysis. Personal Finances and Worker Productivity, 1, 184-189.

Hayslip, Jr. B., Beyerlein, M., \& Nichols, J. A. (1997). Assessing anxiety about retirement: The case of academicians. International Journal of Aging \& Human Development, 44, 15-36.

Henkens, K., Grift, Y., \& Siegers, J. (2002). Changes in female labour supply in the Netherlands 1989-1998: The case of married and cohabiting women. European Journal of Population, 18, 39-57.

Hershey, D. A. (1990). The role of knowledge and experience in structuring problem solving performance (Doctoral dissertation, University of Southern California, 1990). Dissertation Abstracts International, 51, Section 7B.

Hershey, D. A. (2004). Psychological influences on the retirement investor. CSA: Certified Senior Advisor, 22, 31-39.

Hershey, D. A., Brown, C. E., Jacobs, J. M., \& Jackson, J. (2001). Retirees’ perceptions of important retirement decisions. The Southwestern Journal on Aging, 16, 91-100.

Hershey, D. A., Jacobs-Lawson, J. M., \& Neukam, K. N. (2002). Influences of age and gender on workers' goals for retirement. International Journal of Aging \& Human Development, 55, 163-179.

Hershey, D. A., \& Mowen, J .C. (2000). Psychological determinants of financial preparedness for retirement. The Gerontologist, 40, 687-697.

Hershey, D. A., Mowen, J. C., \& Jacobs-Lawson, J. M. (2003). An experimental comparison of retirement intervention seminars. Educational Gerontology, 29, 339-359.

Hershey, D. A., \& Walsh, D. A. (2000/2001). The role of knowledge and experience in structuring financial problem solving performance. Current Psychology, 19, 261-291.

Hershey, D. A., \& Wilson, J. A. (1997). Age differences in confidence ratings on a complex 
financial decision making task. Experimental Aging Research, 23, 257-273.

Hofstede, G. H. (1976). The importance of being Dutch: National and occupation differences in work goal importance. International Studies of Management and Organization, 5, 5-28.

Hofstede, G. H. (1980). Culture's consequences: International differences in work-related values. Beverly Hills: Sage.

ISSA (2004). Gender, retirement, and active aging: Implications for Social Security in long-life societies. International Social Security Association, available: http://www.issa.int/ pdf/research/2gender-policy.pdf.

Jacobs-Lawson, J. M., \& Hershey, D. A. (2005). Influence of future time perspective, financial knowledge, and financial risk tolerance on retirement savings behaviors. Financial Services Review, 14, 331-344.

Kassarjian, H. H. (1971). Personality and consumer behavior: A review. Journal of Marketing Research, 8, 409-418.

Kemp, C. L., Rosenthal, C. J., \& Denton, M. (2005). Financial planning for later life: Subjective understandings of catalysts and constraints. Journal of Aging Studies, 19, 273-290.

Klem, L. (1995). Path analysis. In L. G. Grimm \& P. R. Yarnold (Eds.), Reading and understanding multivariate statistics (pp. 65-97). Washington, D.C.: American Psychological Association.

Kreidl, M. (2000). Perceptions of poverty and wealth in Western and Post-Communist countries. Social Justice Research, 13, 151-176.

Larson, E. (1992). The naked consumer: How our private lives become public commodities. New York: Henry Holt and Company.

Lundeberg, M. A., Fox, P. W., Brown, A. C., \& Elbedour, S. (2000). Cultural influences on confidence: Country and gender. Journal of Educational Psychology, 92, 152-159.

Lusardi, A. (1999). Information, expectations, and savings for retirement. In H. J. Aaron (Ed.), Behavioral dimensions of retirement (pp. 81-115). Washington, DC: Brookings Institution Press.

Lusardi, A. (2000). Explaining why so many households do not save. CRR Working Paper Series, \#203. Boston: Center for Retirement Research.

Mitchell, O. S., \& Moore, J. F. (1998). Can Americans afford to retire? New evidence on retirement saving adequacy. Journal of Risk and Insurance, 65, 371-400. 
Moen, P., Erickson, W. A., Agarwal, M., Fields, V., \& Todd, L. (2000). The Cornell retirement and well being study: Final report. Cornell: Brofenbrenner Life Course Center.

Moore, C. C. (1995). Whose pension is it anyway? Economically targeted investments and the pension funds. Cato Institute Policy Analysis, \#236.

Mowen, J. C. (2000). The 3M model of motivation and personality: Theory and empirical applications to consumer behavior. Boston: Kluwer Academic Press.

Neukam, K. A. (2002). Fear and goal-based planning motives: A psychological model of financial planning for retirement. Master’s thesis completed at Oklahoma State University, Department of Psychology.

Neukam, K. A., \& Hershey, D. A. (2003). Financial inhibition, financial activation, and saving for retirement. Financial Services Review, 12, 19-37.

Nurmi, J. (1992). Age differences in adult life goals, concerns, and their temporal extension: A life course approach to future-oriented motivation. International Journal of Behavioral Development, 15, 487-508.

OECD (2005). Pensions at a Glance: Public policies across OECD countries 2005 edition. Organization for Economic Cooperation and Development, Paris. Available: http://www.oecd.org/dataoecd/44/55/34816545.pdf.

O’Rand, A. M. (1996). The cumulative stratification of the life course. In R. H. Binstock \& L. K. George (Eds.), Handbook of aging and the social sciences, $4^{\text {th }}$ ed. (pp. 188-207). San Diego: Academic Press.

Poortinga, Y. H. (1989). Equivalence of cross-cultural data: An overview of basic issues. International Journal of Psychology, 24, 737-756.

Reday-Mulvey, G. (2005). Working beyond 60: Key policies and practices in Europe. Basingstoke, England: Palgrave Macmillian.

Shiller, R. J. (1999). Human behavior and the efficiency of the financial system. In J. B. Taylor \& M. Woodford (Eds.), Handbook of macroeconomics, Vol. 1C (pp. 1305-1340). New York: Elsevier Science.

Stawski, R. S., Hershey, D. A., \& Jacobs-Lawson, J. M. (2005). Goal clarity and financial planning activities as determinants of retirement savings contributions. Manuscript under review.

Stiles, D. A., Gibbons, J. L., \& Peters, E. (1993). Adolescents’ views of work and leisure in the 
Netherlands and the United States. Adolescence, 28, 473-489.

Szinovacz, M. \& Ekerdt, D. J. (1995). Families and retirement. In R. Blieszner \& V. H. Bedford (Eds.), Handbook of aging and the family (pp. 375-400). Westport, CT: Greenwood Press. Tanzer, N. K. (1995). Cross-cultural bias in Likert-type inventories: Perfect matching factor structures and still biased? European Journal of Psychological Assessment, 11, 194-201.

Taylor, M. A., \& Doverspikke, D. (2003). Retirement planning and preparation. In G. A. Adams \& T. A. Beehr (Eds.), Retirement: Reasons, processes, and results (pp. 53-82). New York: Springer.

UNECE (2004). Gender aspects of social protection and pensions in ageing Europe. United Nations Economic Commission for Europe, Fact Sheet 3. Available: http://www.unece. org/press/pr2004/04gen_n05e.htm.

U.S. Department of Labor (2005). Private pension plan bulletin: Abstract of 2000 form 5500 annual reports. Washington, DC: Author. Available: http://www.dol.gov/ebsa/PDF /2000pensionplanbulletin.PDF.

Van Dalen, H. P., \& Henkens, K. (2002). Early retirement reform: Can and will it work? Ageing and Society, 22, 209-232.

Van Dalen, H. P., \& Henkens, K. (2005a). The double standard in attitudes toward retirement and work. Geneva Papers on Risk and Insurance. 30, 693-710.

Van Dalen, H.P., \& Henkens, K. (2005b). Wie vertrouwt de werknemer zijn pensioengeld toe? (Who Does the Worker Trust in Pension Finance?) Economisch Statistische Berichten, 90, 58-60.

Van de Vijver, F. J. R., \& Leung, K. (1997). Methods and data analysis of comparative research. In J. W. Berry, Y. H. Poortinga, \& J. S. Pandey (Eds.), Handbook of cross-cultural psychology: Vol. 1, Theory and method. Boston, MA: Allyn \& Bacon.

Van Herk, H., Poortinga, Y. H., \& Verhallen, T. M. M. (2004). Response styles in rating scales: Evidence of method bias in data from six EU countries. Journal of Cross-Cultural Psychology, 35, 346-360.

Van Solinge, H., \& Henkens, K. (2005). Couples’ adjustment to retirement: A multi-actor panel study. Journal of Gerontology: Social Sciences, 60B, S11-S20.

Von Bertalanffy, L. (1967). General theory of systems: Applications to psychology. Social Science Information, 6, 125-136. 
Walsh, D. A., \& Hershey, D. A. (1993). Mental models and the maintenance of complex problem solving skills into old age. In J. Cerella, J. Rybash, W. Hoyer, and M. L. Commons (Eds.), Adult information processing: Limits on loss (pp. 553-584). New York: Academic Press.

World Bank (1994). Averting the old age crisis: Policies to protect the old and promote growth. Washington: DC: Author.

Yakoboski, P., \& Dickemper, J. (1997). Increased saving but little planning: Results of the 1997 Retirement Confidence Survey. Employee Benefits Research Institute Brief, Issue Brief 191.

Yuh, Y., \& DeVaney, S. A. (1996). Determinants of couples’ defined contribution retirement funds. Financial Counseling and Planning, 7, 31-38. 


\section{Footnotes}

${ }^{1}$ Following the recommendations of Klem (1995), this trimming process took place in two stages. In the first stage, Dutch and American hierarchical regression models are separately estimated with all possible predictors. In the second stage, the models are again estimated, only after predictors with standardized beta weight values between -.20 and .20 (in the initial model) have been omitted. According to Klem, this approach allows for the reduction of unnecessary clutter in a path analysis, and at the same time, it allows one to achieve incrementally more valid parameter estimates. Only the results of the trimmed models are presented in text. This is because trimming predictors with small beta weights did not fundamentally change the major regression findings. Across all eight regressions (four Dutch; four American), four paths were trimmed from the Dutch models and three were removed from the American models.

${ }^{2}$ In age-based subgroup analyses not reported in text, we found that goal clarity scores among 25-35 year old Dutch workers $(\mathrm{M}=1.88, \mathrm{SD}=.77)$ were appreciably lower than those of American respondents of the same age $(\mathrm{M}=3.02, \mathrm{SD}=.94), t(403)=12.32, p<.01$. 
Table 1: Mean Scores and Standard Errors (in parentheses) on Structural Variables for Dutch and American Samples

\begin{tabular}{lccc}
\hline & Americans & Dutch & p-level \\
\hline Sample Size & 429 & 988 & - \\
Gender composition (\% male) & 49.9 & 63.2 & .01 \\
Age & 43.91 & 42.27 & \\
& $(.51)$ & $(.30)$ & .01 \\
Years of Education & & & \\
& 15.55 & 14.41 & \\
Annual Household Income (\$USD) & $(.11)$ & $(.08)$ & .01 \\
& & & \\
\end{tabular}

Note: $t$-tests were used to compare mean scores across groups 
Table 2: Scale Characteristics, Psychometric Properties, and Wording of Survey Items for the Psychological and Retirement

Variables.

\begin{tabular}{|c|c|c|c|c|c|c|}
\hline Scale Name \& Source & $\begin{array}{c}\text { American } M \\
\left(S E_{M}\right)\end{array}$ & $\begin{array}{l}\text { Dutch } M \\
\qquad\left(S E_{M}\right)\end{array}$ & $\begin{array}{c}p- \\
\text { level }\end{array}$ & $\begin{array}{c}\text { Scale } \\
\text { Characteristics }\end{array}$ & Sample Item \& Response Format & $\begin{array}{l}\text { Psychometric } \\
\text { Properties }\end{array}$ \\
\hline $\begin{array}{l}\text { Future Time Perspective } \\
\text { Hershey \& Mowen (2000); } \\
\text { Neukam (2002) }\end{array}$ & $\begin{array}{l}3.38 \\
(.039)\end{array}$ & $\begin{array}{l}3.13 \\
(.025)\end{array}$ & .01 & $\begin{array}{l}\text { 4-item scale. A single score } \\
\text { for this measure was } \\
\text { constructed by calculating an } \\
\text { unweighted mean. Higher } \\
\text { scores correspond to longer } \\
\text { future time perspectives. }\end{array}$ & $\begin{array}{l}\text { I enjoy thinking about how I will live years } \\
\text { from now in the future. } \\
\qquad 1 \text { = strongly disagree; } 5 \text { = strongly agree }\end{array}$ & $\begin{array}{c}\text { American } \alpha=.68 \\
\text { Dutch } \alpha=.59\end{array}$ \\
\hline $\begin{array}{l}\text { Retirement Goal Clarity } \\
\text { Hershey, Mowen \& } \\
\text { Jacobs-Lawson (2003); } \\
\text { Stawski, Hershey \& } \\
\text { Jacobs-Lawson (2005) }\end{array}$ & $\begin{array}{l}3.41 \\
(.043)\end{array}$ & $\begin{array}{c}2.20 \\
(.028)\end{array}$ & .01 & $\begin{array}{l}\text { 3-item scale (same scoring } \\
\text { procedure as above). Higher } \\
\text { scores correspond to higher } \\
\text { levels of goal clarity. }\end{array}$ & $\begin{array}{l}\text { I have thought a great deal about quality of } \\
\text { life in retirement. } \\
\qquad 1 \text { = strongly disagree; } 5 \text { = strongly agree }\end{array}$ & $\begin{array}{c}\text { American } \alpha=.76 \\
\text { Dutch } \alpha=.82\end{array}$ \\
\hline $\begin{array}{l}\text { Perceived Financial } \\
\text { Knowledge } \\
\text { Hershey \& Mowen (2000); } \\
\text { Jacobs-Lawson \& Hershey } \\
\text { (2005) }\end{array}$ & $\begin{array}{c}3.24 \\
(.042)\end{array}$ & $\begin{array}{c}3.18 \\
(.027)\end{array}$ & ns & $\begin{array}{l}\text { 3-item scale (same scoring } \\
\text { procedure as above). Higher } \\
\text { scores correspond to higher } \\
\text { levels of perceived financial } \\
\text { knowledge. }\end{array}$ & $\begin{array}{l}\text { I know more than most people about } \\
\text { retirement planning. } \\
\qquad 1=\text { strongly disagree; } 5 \text { = strongly agree }\end{array}$ & $\begin{array}{c}\text { American } \alpha=.72 \\
\text { Dutch } \alpha=.73\end{array}$ \\
\hline $\begin{array}{l}\text { Retirement Planning } \\
\text { Activity Level } \\
\text { Hershey \& Mowen (2000) }\end{array}$ & $\begin{array}{l}3.22 \\
(.061)\end{array}$ & $\begin{array}{c}2.84 \\
(.039)\end{array}$ & .01 & $\begin{array}{l}\text { 3-item scale (same scoring } \\
\text { procedure as above). Higher } \\
\text { scores correspond to more } \\
\text { planning activities. }\end{array}$ & $\begin{array}{l}\text { Calculations have been made to estimate } \\
\text { how much money I need to save to retire } \\
\text { comfortably. } \\
\qquad 1=\text { strongly disagree; } 5 \text { = strongly agree }\end{array}$ & $\begin{array}{c}\text { American } \alpha=.88 \\
\text { Dutch } \alpha=.86\end{array}$ \\
\hline $\begin{array}{l}\text { Perceived Savings } \\
\text { Adequacy } \\
\text { (not previously published) }\end{array}$ & $\begin{array}{c}2.88 \\
(.056)\end{array}$ & $\begin{array}{c}3.17 \\
(.036)\end{array}$ & .01 & $\begin{array}{l}\text { Single item indicator. Higher } \\
\text { scores correspond to higher } \\
\text { levels of perceived savings } \\
\text { adequacy. }\end{array}$ & $\begin{array}{l}\text { I am saving enough to retire comfortably. } \\
\qquad 1 \text { = strongly disagree; } 5 \text { = strongly agree }\end{array}$ & $\mathrm{n} / \mathrm{a}$ \\
\hline
\end{tabular}

Note: t-tests were used to compare mean scores across groups. Mean scores for the constructs are estimated means that control for age, gender, education and income. 
Table 3: Standardized Beta Weights and Accompanying t-values from Regressing the Psychological and Retirement Variables on the Four Structural Variables

\begin{tabular}{|c|c|c|c|c|c|}
\hline \multirow[b]{2}{*}{ Construct } & \multicolumn{2}{|c|}{ Americans } & \multicolumn{2}{|c|}{ Dutch } & \multirow{2}{*}{$\begin{array}{r}\text { Difference } \\
p \text {-value }\end{array}$} \\
\hline & $\beta$ & $t$-value & $\beta$ & $t$-value & \\
\hline \multicolumn{6}{|l|}{ Future Time Perspective } \\
\hline Chronological Age & .04 & 0.74 & .10 & $3.06 *$ & .30 \\
\hline Gender & -.09 & 1.91 & .00 & 0.14 & .07 \\
\hline Annual Household Income & .28 & $5.49 * *$ & .06 & 1.88 & .00 \\
\hline Years of Education & .04 & 0.81 & .05 & 1.69 & .99 \\
\hline & \multicolumn{2}{|c|}{$R^{2}=9.9 \%$} & \multicolumn{2}{|c|}{$R^{2}=1.8 \%$} & \\
\hline \multicolumn{6}{|l|}{ Retirement Goal Clarity } \\
\hline Chronological Age & .18 & $3.82 * *$ & .30 & $9.80 * *$ & .02 \\
\hline Gender & -.05 & 1.07 & -.11 & $3.64 * *$ & .29 \\
\hline Annual Household Income & .23 & $4.66^{* *}$ & .04 & 1.45 & .00 \\
\hline \multirow[t]{2}{*}{ Years of Education } & -.04 & 0.86 & -.09 & $3.10 * *$ & .50 \\
\hline & \multicolumn{2}{|c|}{$R^{2}=11.6 \%$} & \multicolumn{2}{|c|}{$R^{2}=12.9 \%$} & \\
\hline \multicolumn{6}{|l|}{ Perceived Financial Knowledge } \\
\hline Chronological Age & .03 & 0.56 & .11 & $3.40 * *$ & .15 \\
\hline Gender & -.09 & $1.96 *$ & -.21 & $6.68^{* *}$ & .05 \\
\hline Annual Household Income & .29 & $5.81 * *$ & .09 & $2.83^{*}$ & .00 \\
\hline \multirow[t]{2}{*}{ Years of Education } & $.11^{*}$ & 2.39 & .06 & 1.91 & .20 \\
\hline & \multicolumn{2}{|c|}{$R^{2}=13.8 \%$} & \multicolumn{2}{|c|}{$R^{2}=7.4 \%$} & \\
\hline \multicolumn{6}{|c|}{ Retirement Planning Activity Level } \\
\hline Chronological Age & .16 & $3.40 * *$ & .04 & 1.36 & .12 \\
\hline Gender & -.11 & $2.41 *$ & -.16 & $5.03 * *$ & .21 \\
\hline Annual Household Income & .27 & $5.62 * *$ & .04 & 1.22 & .00 \\
\hline \multirow[t]{2}{*}{ Years of Education } & .09 & 1.86 & .02 & 0.54 & .09 \\
\hline & \multicolumn{2}{|c|}{$R^{2}=17.4 \%$} & \multicolumn{2}{|c|}{$R^{2}=3.2 \%$} & \\
\hline \multicolumn{6}{|l|}{ Perceived Savings Adequacy } \\
\hline Chronological Age & .09 & 1.86 & .06 & 1.84 & .60 \\
\hline Gender & -.10 & $2.30 *$ & -.13 & $3.99 * *$ & .82 \\
\hline Annual Household Income & .35 & $7.22 * *$ & .04 & 1.17 & .00 \\
\hline \multirow[t]{2}{*}{ Years of Education } & .00 & 0.10 & .01 & 0.24 & .87 \\
\hline & \multicolumn{2}{|c|}{$R^{2}=17.2 \%$} & \multicolumn{2}{|c|}{$R^{2}=2.4 \%$} & \\
\hline
\end{tabular}

${ }^{\mathrm{a}}$ The difference $p$-value is based on standardized beta weight comparisons across groups. 

adequacy.

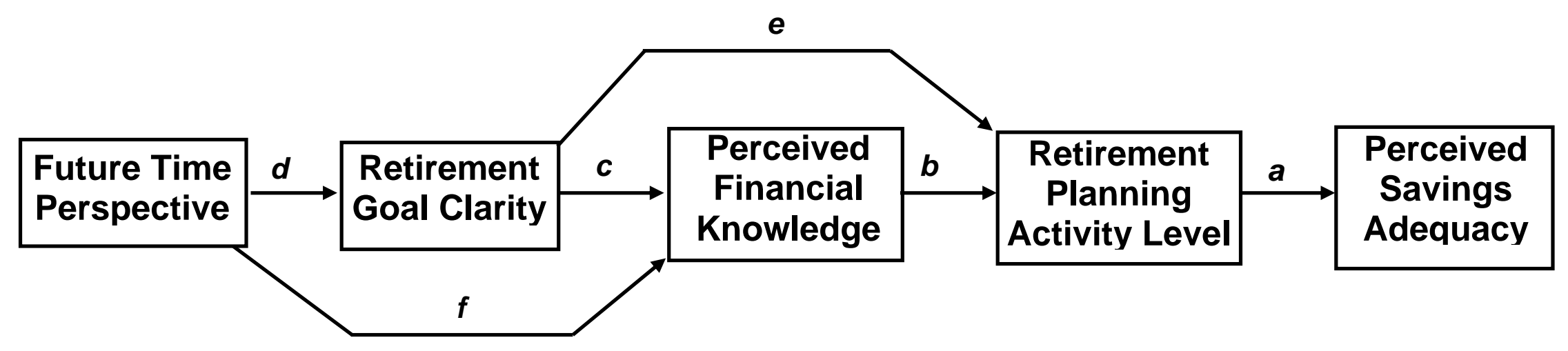


Figure 2. Dutch path analysis model of the psychological influences on planning activities and perceived savings. All path coefficients shown are standardized beta weights and all exceed the .05 significance level.

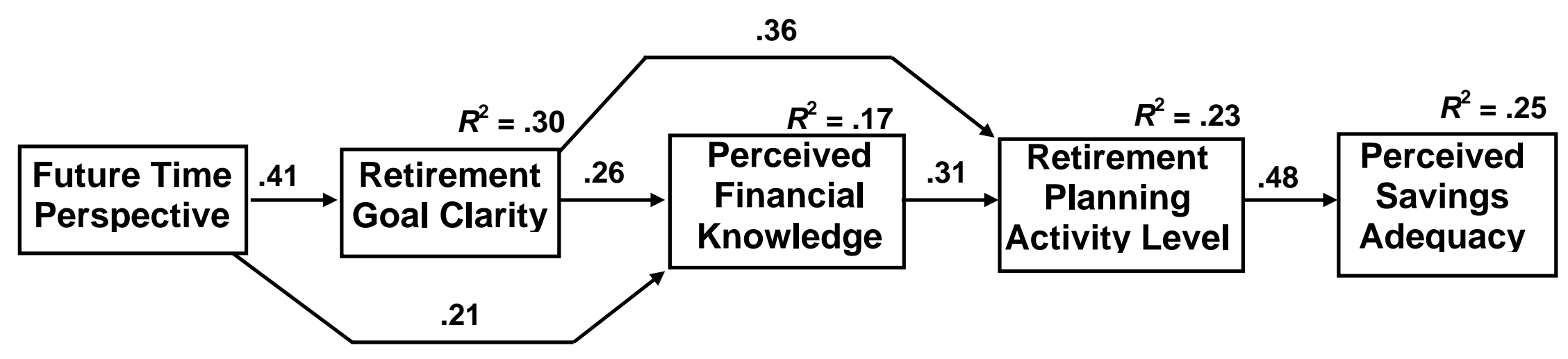


Figure 3. American path analysis model of the psychological influences on planning activities and perceived savings. All path coefficients shown are standardized beta weights and all exceed the .05 significance level

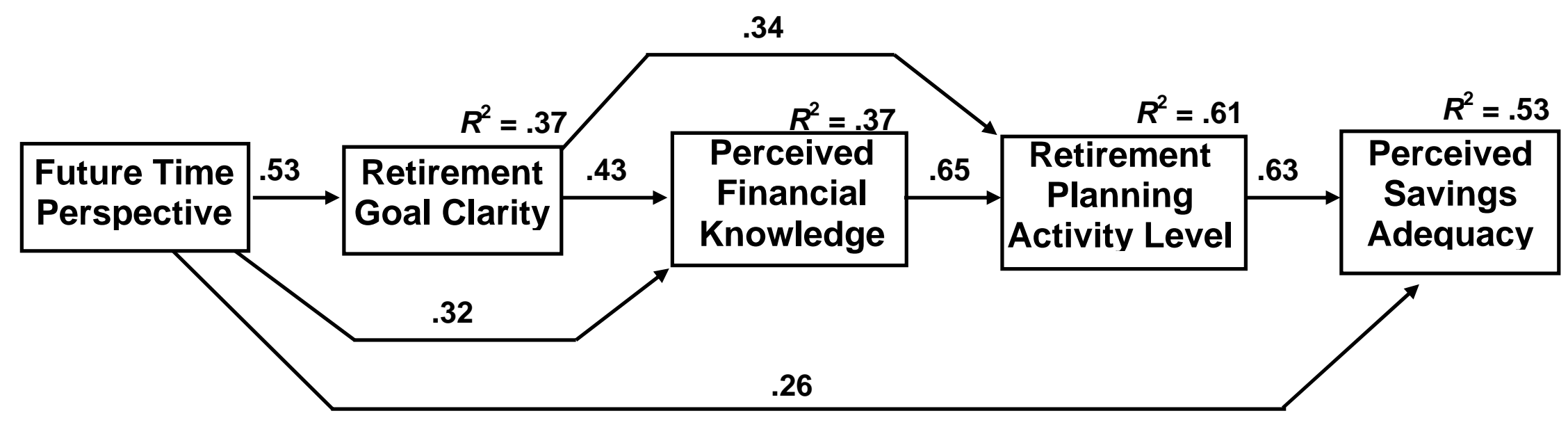

